\title{
A Tracer Streamline Practice For Re-Evaluation Waterflood Pattern To Introduce A Cyclic Water Injection Scheme
}

\author{
Dike Fitriansyah Putra ${ }^{1 *}$, Lazuardhy Vozika Futur ${ }^{1}$, Mursyidah Umar ${ }^{1}$ \\ ${ }^{1}$ Department of Petroleum Engineering, Islamic University of Riau, Jl. Kaharuddin Nasution No.113 Pekanbaru 28284, Indonesia
}

\author{
* Corresponding author : dikefp@eng.uir.ac.id \\ Tel.: +62-812-987-44099 \\ Received: Nov 8, 2019; Accepted: Aug 30, 2021. \\ DOI: 10.25299/jgeet.2021.6.3.4064
}

\begin{abstract}
Waterflood introduces in the oil field a couple of years ago. Several waterflood schemes have been implemented in the fields to get the best incremental oil, such as peripheral injection, pattern waterflood, and etcetera. Many waterflood schemes are not working properly to boost the oil recovery due to unpredicted and unexpected water tide array. Then, the tracer practice started to be used for getting a better picture of the transmissibility reservoir as well as the direction of water pathway. This practice honors the parameters, such pressure, water cut, GOR, and rates. The streamline modeling is used to map the tracer, and it concludes that the selection of location of the injector should be based on the highest oil recovery achieved. Subsequently, the cyclic water injection method is one alternative. Apparently, this approach yields a quantify incremental recovery. This research utilizes the pressure different approach to figure out the route of water in the formation. The inter-well tracer technique in this modeling study is a tool to review communication between injectors and producers in the existing pattern. Many scenario should be tried to find the best options for the new pattern opportunities. In parallel, a innovative scheme of waterflood technique should be implemented too for escalating oil recovery. The stream pathway observes a new potential of the waterflood scheme. It is called "cyclic injection" scheme. The novelty of this approach is the ability to solve the poor sweep efficiency due to improper pathway of water influx in the oil bearing".
\end{abstract}

Keywords: Tracer Test, Cyclic Water Injection, Water-flood, Streamlines

\section{Introduction}

The possibility of increasing oil productivity in the field is to utilize water injection to displace oil to producers. The water enters the formation and stimulate the production by increasing the amount of oil produced from the field (Asadollahi, 2012). Unfortunately, under improper pressure maintaining system as well as the higher offtake rate impact the decline of reservoir pressure.

The water injection is the most popular method to boost oil production. Notwithstanding many characteristics of the reservoir are favorable, there are also some characteristics of the reservoir that are detrimental, such as reservoir heterogeneity, especially the value of high permeability, it reflects poorly on water injection. The very high permeability can disturb the sweeping effect in the waterflood scheme (Alhuthali et al., 2007). Waterflood conformance control on reservoir heterogeneity is a common challenge in an oil field (Thrasher et al., 2016).

The study's aim is to review the existing pattern performance by utilizing the inter-well tracer test as a tool. Then, a streamline simulator is used to analyze the tracer test flow path. Afterward, we discover the best scenario for the new pattern as well as a new scheme of waterflood to increase oil recovery. This study focuses on selecting the best scenario based on several parameters, including tracer time breakthrough, tracer production concentration, cumulative tracer production, and how the tracer flows in the streamlined model.

In the Petroleum Industry, tracer tests are typically used to evaluate the communication between the injector and producer as well as the reservoir transmisibility. The tracer survey provides a variety of information about the heterogeneity of the reservoir, such as the fluid flow path and conformance problem. The flow path is defined as preferential pathways reservoir fluid to move from one point (injection wells) to the other point in the reservoir (production wells). This path is geologically homogeneous or highly heterogeneous due to layering, thief zones, natural fracturing, faulting, or flow-barriers. That means, it is necessary to establish flow paths using a fluid carrier containing various kinds of tracers (Guan et al., 2005).

The usefulness of the water injection tracer is to monitor the movement of water based on the assumption that the movement of the tracer reflects the movement of injected water. How true it depends on how closely tracer injection followed by formation water without a significant loss and delay. It depends how good a tracer chemical composition that is facing reservoir property (Zemel, 1995), As a rule of thumb, $40 \%$ tracer must be produced to ensure the production well-effluent tracer profiles reliable analysis (Hao et al., 2011).

Cyclic Water Injection (CWI) is a periodic water injection technique. This technique introduced in 1960 and aims to increase production in the field, which has a heterogeneous reservoir (Yang et al., 2006). Since then, the cyclic water injection has several times applied in some fields in the world, in China, the United States, and Russia. Those have shown positive results (Shchipanov et al., 2008)

CWI has a result that is not as good as other EOR methods. Because of a less incremental recovery when compared with other EOR methods, the CWI is considered an advanced waterflood (Rublev et al., 2012).

CWI as a further development of conventional water injection based on two mechanisms (Langdalen, 2014):

1. Changing the water injection rate. 
2. Change the water injection pattern.

Basically, during cyclic water injection, the injection rate introduces alternately between the high rate and the regular rate or the low rate and stop the injection condition. The rate of water injection is directly proportional to the injection pressure. While the injection rate is high, then the pressure reservoir rises accordingly. Oppositely, whereas low injection rate into the reservoir cause pressure drops significantly. Once cyclic injection takes place, there should be a pressure pulse between the layers (Shchipanov et al., 2008)

As for some of the advantages of the application of cyclic water injection, including:

1. Increase oil production (Perez et al., 2014)

2. Decrease water cut (Perez et al., 2014)

Almost no cost incurred compared to conventional water injection (Shchipanov et al., 2008) Cyclic water injection based on two parameters:

1. Pressurizing (Half-Cycle)

Water injects in high flow rates, and the hydrocarbons produced in the same flow rate. The high flow rate on continuous water injection, the reservoir pressure increase significantly even may exceed the initial reservoir pressure. The increasing of the pressure on the highpressure zone in the high permeability region can push water toward the low permeability region that is not swept yet by the scheme of continuous water injection.

2. Depressurizing (Half-Cycle)

Water injection stops, the reservoir pressure is steppingdown, and then the water is sweeping away andreplacing hydrocarbons located in the lower permeability region. Meanwhile, hydrocarbons that move away is heading from the high permeability zones towards the production wells.

\section{Methodology}

The streamline simulation is a numerical modeling that uses an implicit calculation for solving pressure equation as well as an explicit estimation for solving saturation/conservation equation (Al-Najem et al., 2012). The software simulator is Petrel 2017 Schlumberger; starting with several input data, then building 3D grid initially. It utilizes the finite difference approximation to derive pressure distribution for generating instantaneous velocity vectors perpendicular to the calculated pressure contours. The streamlines is traced by the velocity at the time of interest under a time varying-velocity (Putra et al., 2021).

The reservoir model is named PLC field. It can be categorized as a vast reservoir with porosity range within $30 \%$ to $35 \%$, and the average permeability is $800 \mathrm{mD}$ laterally. The current reservoir pressure is 310 bar, and the current temperature reservoir is $74^{\circ} \mathrm{C}$. The datum point is in 1850 ftTVD SS, and the Oil Gravity value is within $32-36^{\circ} \mathrm{API}$ and GOR value of $100 \mathrm{v} / \mathrm{v}$. In this study, six scenarios are evaluated (Table 1) and set by using a ratio of $1: 1$ and $1: 2$.

Fig 1 to Fig 4 show the history matching stage conducted before the tracer streamline (Putra, 2007) .

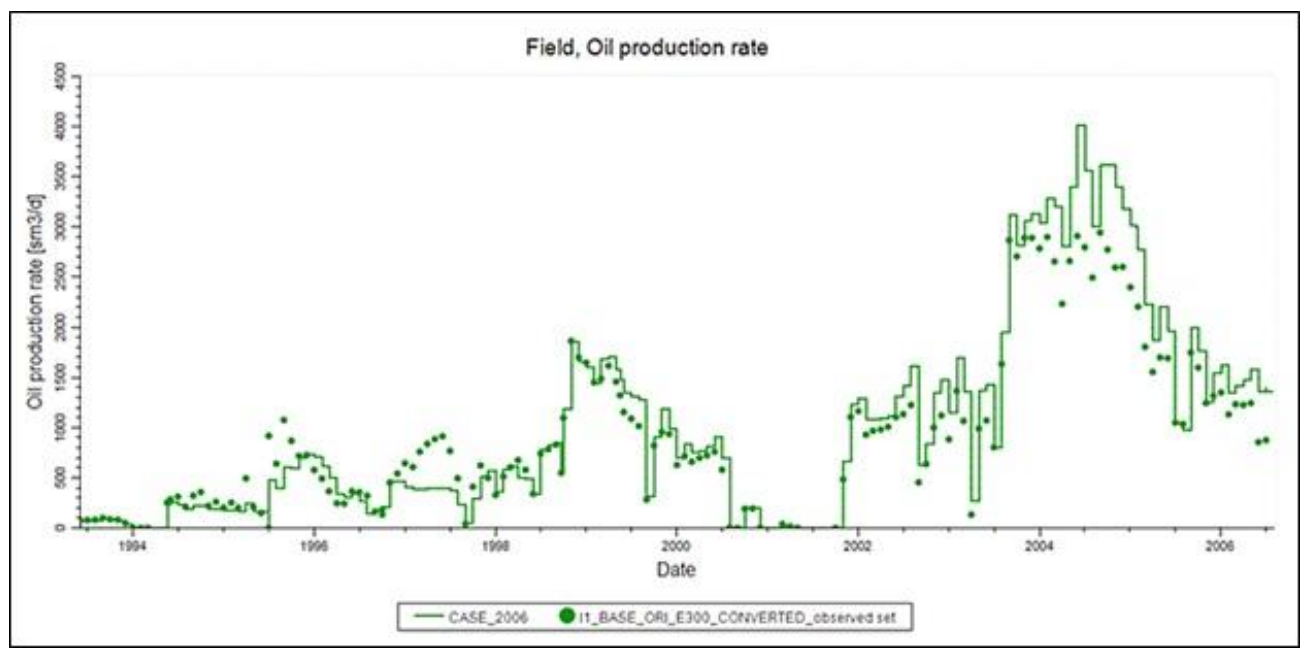

Fig 1. History Matching of Oil Production (Putra, 2007)

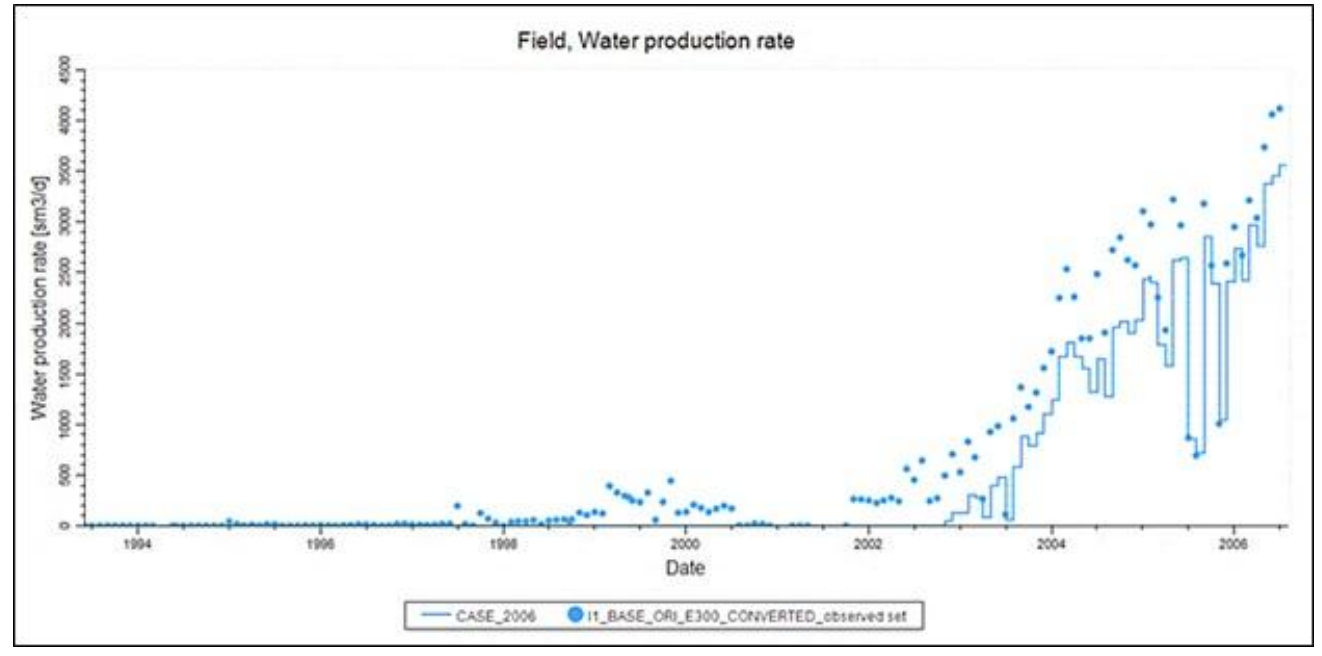

Fig 2. History Matching of Water Production (Putra, 2007) 


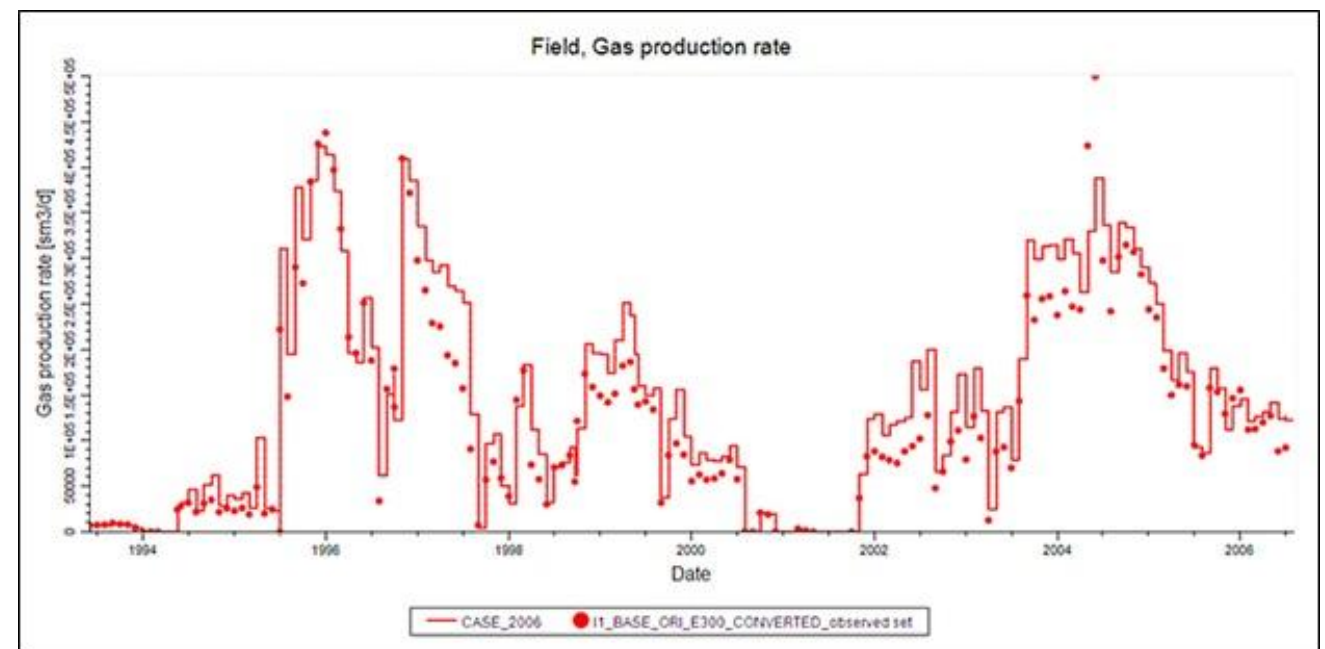

Fig 3. History Matching of Gas Production (Putra, 2007)

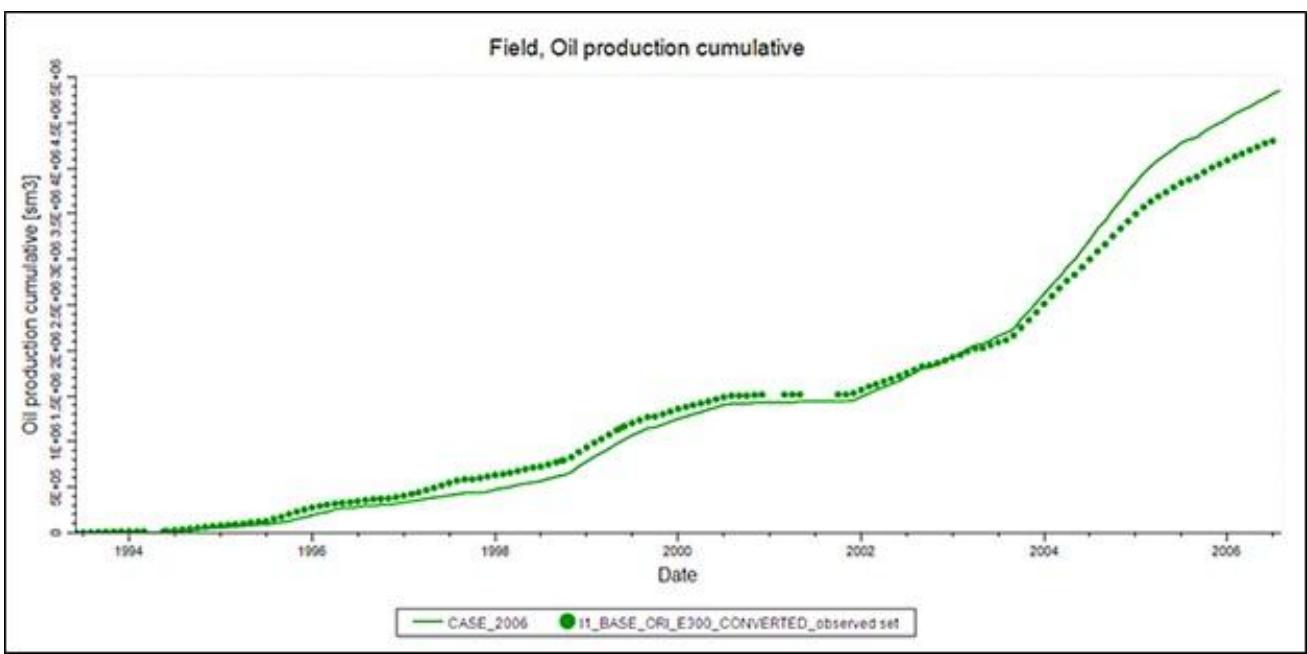

Fig 4. History Matching of Oil Cumulative (Putra, 2007)

Table 1. Base case and six scenarios in the simulation model of cyclic water injection

\begin{tabular}{cccc}
\hline Case & $\begin{array}{c}\text { Injection Duration } \\
\text { (Day) }\end{array}$ & $\begin{array}{c}\text { Stop Injection Duration } \\
\text { (day) }\end{array}$ & Injection Rate $\left(\mathrm{sm}^{3}\right)$ \\
\hline Base Case & Continuous & - & 5,220 \\
Scenario \#1 & 1 & 1 & 10,440 \\
Scenario \#2 & 1 & 2 & 15,660 \\
Scenario \#3 & 7 & 7 & 10,440 \\
Scenario \#4 & 7 & 14 & 15,660 \\
Scenario \#5 & 30 & 30 & 10,440 \\
Scenario \#6 & 30 & 60 & 15,660 \\
\hline
\end{tabular}

\section{Result}

\subsection{Injection Wells Screening and Selection}

In the PLC field, there are two existing water injection wells; those are A-41BWAT and A-41. Two tracer injection tests conducted to screen the appropriate injector for a cyclic candidate well.

\section{a. Tracer test in 41BWAT}

In A-41BWAT, tracer WN1 with $25.000 \mathrm{ppm}$ concentrations is injected about $5,220 \mathrm{sm}^{3}$ on July $1 \mathrm{st}, 2006$, and continued until the end of the simulation run. The total tracer produced on production wells A-36 up to $1,816.29 \mathrm{sm}^{3}$ or $34.795 \%$ of the injected tracer volume, A-40 up to $1,163.85$ $\mathrm{sm}^{3}$ or $22.296 \%$ of the tracer injected, and B-39B is $470.59 \mathrm{sm}^{3}$ or $9.015 \%$ of the injected tracer, the total data of reproduced tracer approximately $66.106 \%$ on injection applied to A41BWAT.

Fig shows the flow pattern of A-41BWAT toward production wells. If the water injected establishes flow pattern as Fig, the water that passes through the flow path towards the A-36 well is 0.42 fraction, the water that passes through the flow path towards the A- 40 well is 0.33 fraction, whereas the water passing through a flow path towards B-39B well is 0.25 fraction. Fig displays the layout of the wells to A-41BWAT as well as their distances. 


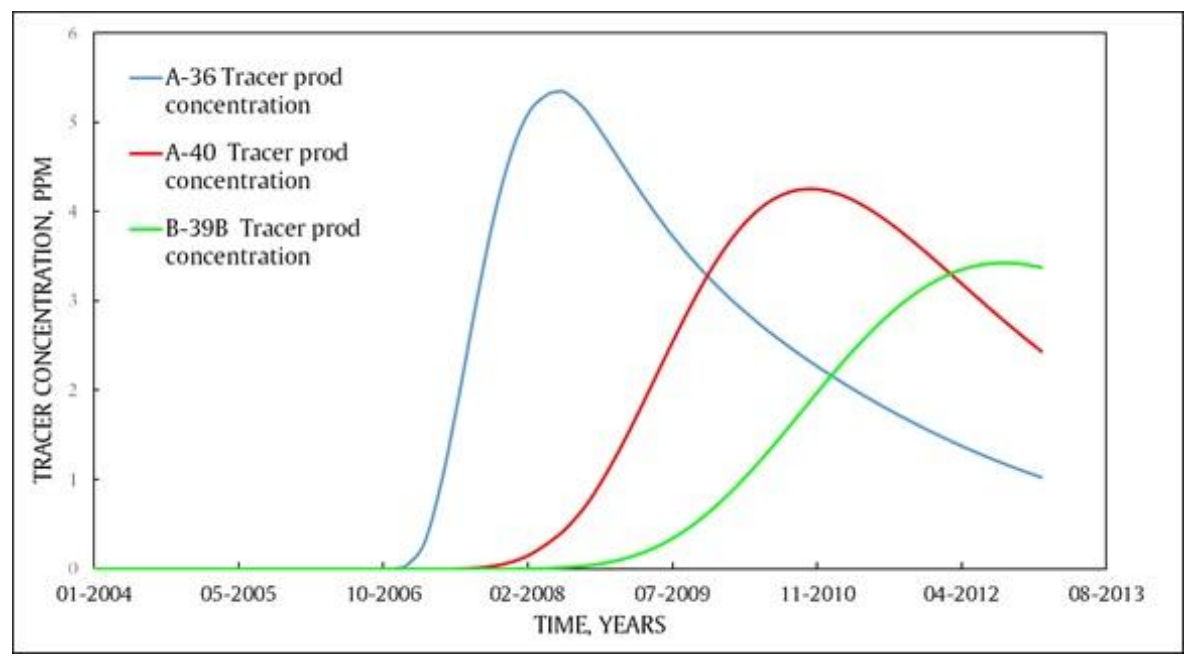

Fig 5. Tracer Production Concentration vs Time (WN1)

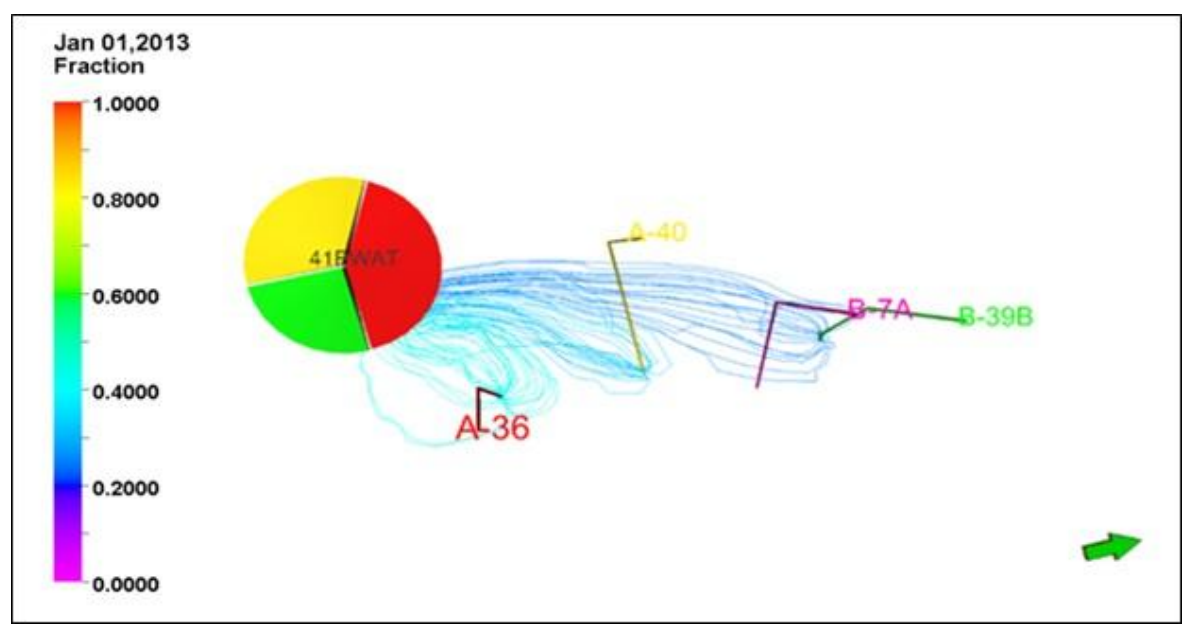

Fig 6. The flow pattern of wells A-41BWAT toward production wells

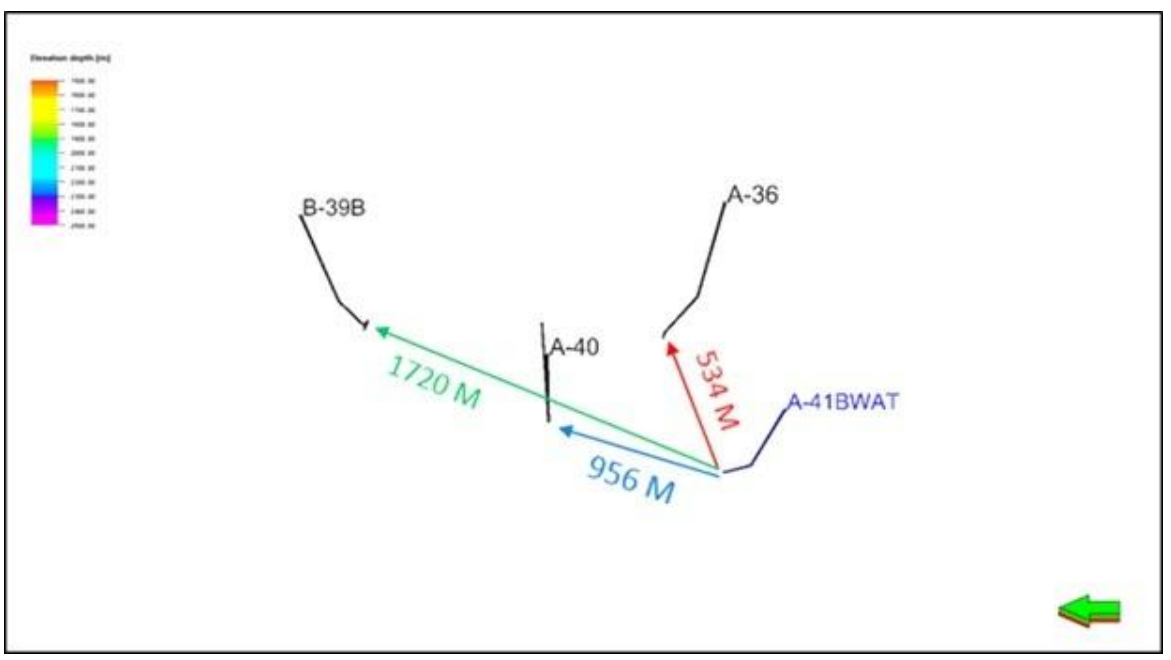

Fig 7. Layout wells and their distances to the injector (A-41BWAT)

\section{b. Tracer test in A-41 well}

A-41, it has been injected tracer, WN2 with concentration $25.000 \mathrm{ppm}$, and volume about $5,220 \mathrm{sm}^{3}$ on July $1 \mathrm{st}, 2006$ and at the end of the simulation run, how much tracer has reproduced along with hydrocarbons is used as a benchmark to A-41BWAT whether this well is worthy for injector that can sweep fluid and raise pressure around the production well. The total tracer produced on producer A-36 up to $1,949.89 \mathrm{sm}^{3}$ or $37.354 \%$ of the tracer injected volume, A-40 is $1,180.546 \mathrm{sm}^{3}$ or $22.616 \%$ of the tracer injected, and B-39B is $442.242 \mathrm{sm}^{3}$ or $8.472 \%$ of the tracer injected, then the total volume tracer reproduced approximately $68.442 \%$ of volume injected.

Fig 9. shows the flow pattern of wells A-41 toward the production well. The water that passes through the flow path 
towards A-36 is 0.45 fraction; the water flow towards A-40 is 0.32 fraction, whereas the water towards $\mathrm{B}-39 \mathrm{~B}$ is 0.23 fraction.

displays the layout of the wells to A-41 as well as their distances.

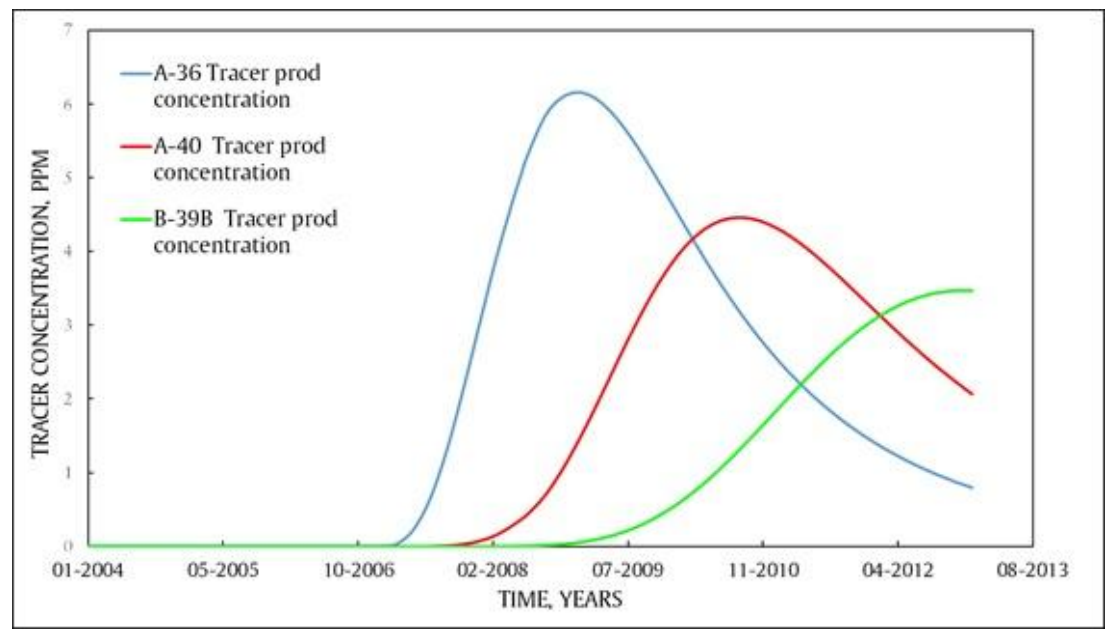

Fig 8. Tracer Production Concentration vs. Time (WN2)

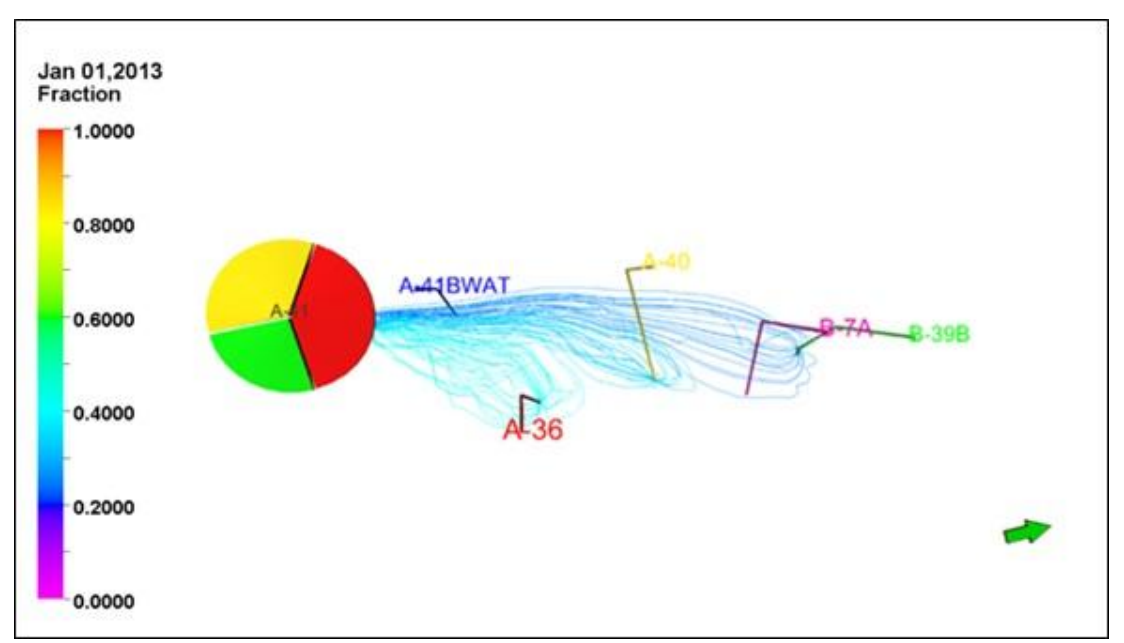

Fig 9. The flow pattern of wells A-41 toward the production well

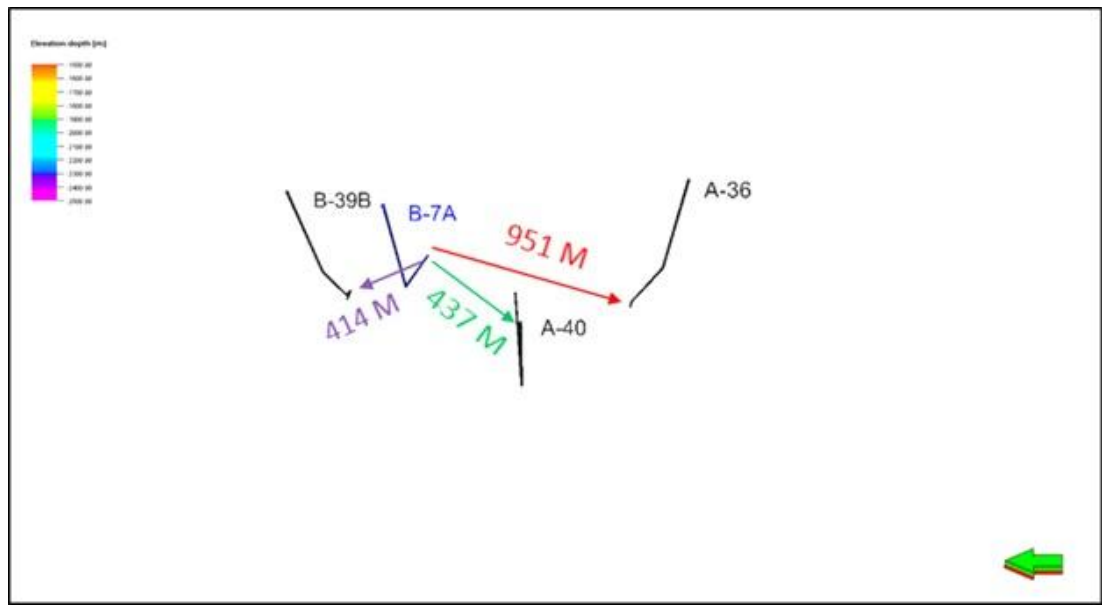

Fig 106. Layout wells and their distances to the injector (A-41)

\subsection{Continuous Water Injection}

A benchmark between continuous water injection as a base case and water cycle injection as a study case is a comparison tool. The base case is continuous flowing injection at the rate of $5,220 \mathrm{sm}^{3}$. Fig 11 shows that without water injection at 5,220 sm3, reservoir pressure drops by 3.806 bar per year. Therefore, it is necessary to perform the water injection to maintain reservoir pressure. Fig 12 shows the performance of the production and injection since 2004. This scheme earned total oil and gas production amounted to $6,477,308 \mathrm{sm}^{3}$ and $828,968,960 \mathrm{sm}^{3}$, respectively. 


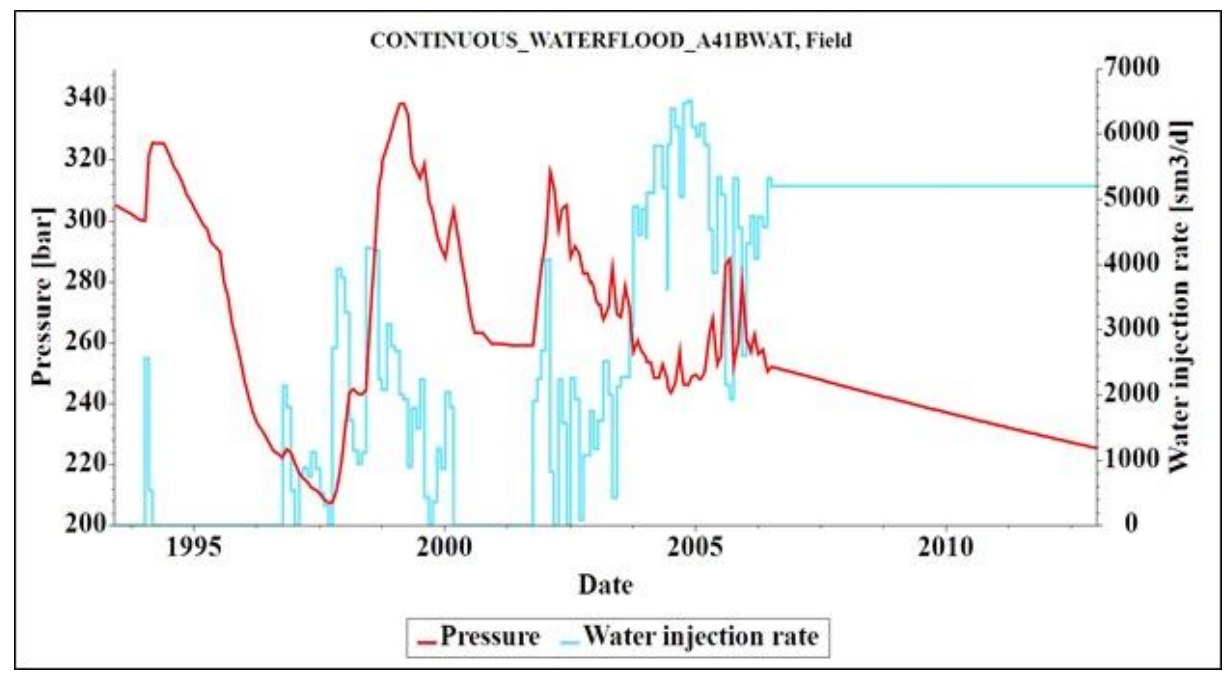

Fig 117. Pressure and injection rates base case

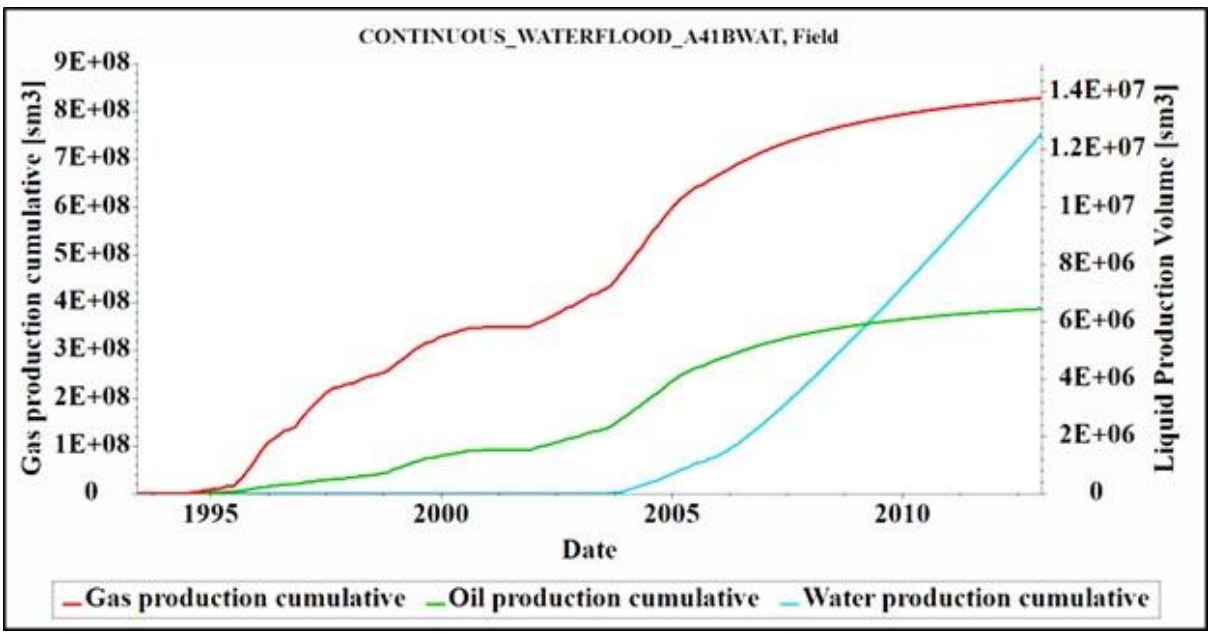

Fig 128. Oil, gas, and water production rates Field PLC (Continuous Water)

\subsection{Cyclic Water Injection}

It is having selected the candidate injector for the water cycle well, which is A-41. The selection parameter is bottom hole pressure at the injectors when A-41BWAT or A-41 serves as the injector. The bottom hole pressure in A-41BWAT exceeds the fracture pressure of the formation. It can impact formation damage. Fig 13 shows bottom hole pressure in the well A-41BWAT reached 450.99 bar, while the fracture pressure of the formation is the PLC field - first segment is 357.6 bar. It is found in the research conducted by (Bale, 2008). Oppositely, the A-41 has a bottom hole pressure of 302.18 bar, which is still quite low from the fracture pressure limit. Hence A-41 is appropriate and suitable to be the cyclic water injector.

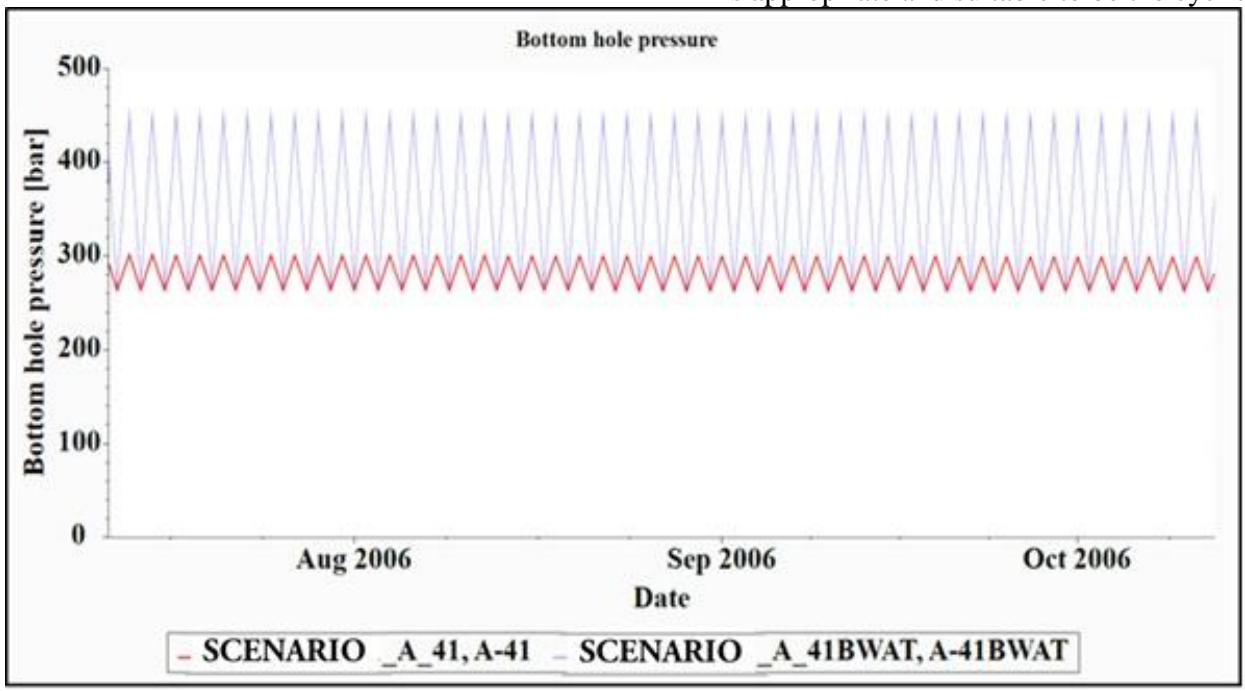

Fig 139. Bottom hole pressure in the well A-41 and A-41BWAT (Cyclic Water Injection) 


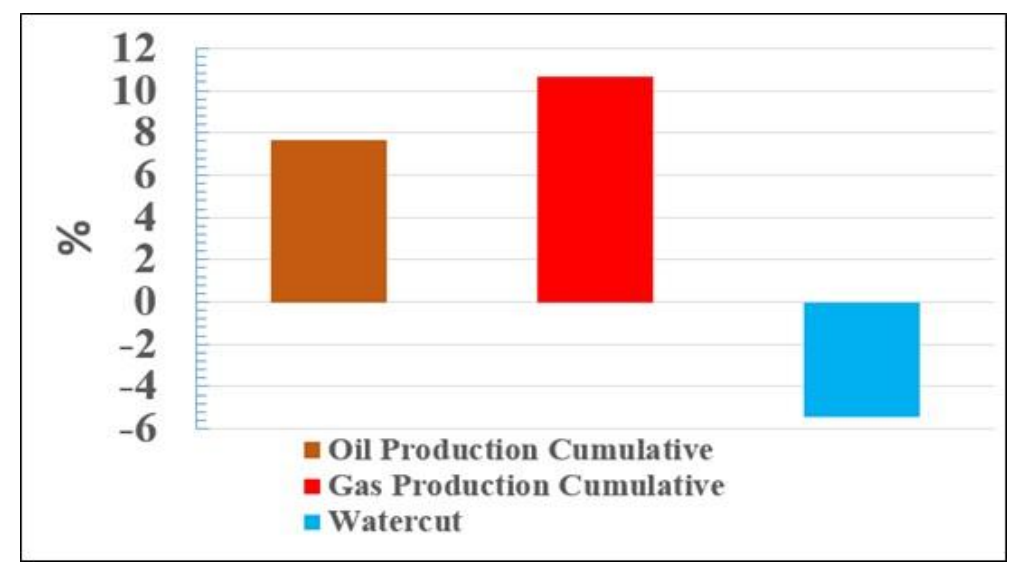

Fig 1410. Incremental Oil and Gas Production and Watercut Decline compare to base-case

\subsection{The Simulation Result for Each Scenario}

Table 2. displays the scenario with parameters, such as values cumulative oil production, cumulative production of gas, water cut average, and peak values of different BHP. The results table exhibits scenario \#4 has a higher value of oil production cumulative and gas production cumulative. Oppositely, scenario 4 has a decline water-cut, meanwhile bottom hole pressure at 347.729 bar. It is lower 10 bar than the fracture pressure limit.

Fig 1410. shows the incremental of oil up to $7.6 \%$ and gas up to $10.7 \%$; meanwhile, water decline down to $5.45 \%$ from scenario \#4.

The oil \& gas incremental trend of this study is close to the result of the field trial at the oil field of East Unity, Sudan, in the year 2012. According to research conducted by (Musa and Ibrahim, 2012) The East Unity oil field can provide oil gains incremental within range 2 to $7 \%$. The incremental of gas production is obtained up to $10.68 \%$, while the water-cut drops down to $5.4 \%$. Another research has been conducted by (Yang et al., 2006) in the Gudao field, and the study obtained the water-cut reduction down to 0.2 to $3 \%$. These phenomena show that the cyclic water injection scheme can be an opportunity to improve water-flood field performance.

\section{a. The influence of cyclic water injection to the flow rate of oil and gas}

The cyclic water injection scheme can alter the flow rate of oil and gas as well as the flow path. This phenomenon is impacted by pressurizing and depressurizing phase. The pressurizing phase pushes the water into the zone that has not reached yet by continuous water injection. The depressurizing phase has a reverse flow from the low permeability zone towards the high permeability zone. It impacts oil mobility from the trap sector due to sucking occurrence. Indriecty, it improves production withdrawal to the producer.

Fig 15 show the up and down curves of scenario \#4 compared to the base case in terms of oil and gas production. In the pressurizing phase, the production rate goes down because the water sweeps a high permeability zone. Meanwhile, in the depressurizing phase, oil flow rate goes up because the reverse flow from the low permeability zone towards the high permeability zone carries residual oil in it. This phenomenon has been stated by (Langdalen, 2014) that the increase of oil production in cyclic water flooding is provided within the depressurizing phase.

Table 2. Parameters of Oil and Gas cumulative, Water cut and Peak BHP

\begin{tabular}{|c|c|c|c|c|c|}
\hline No. & The model name & $\begin{array}{l}\text { Oil Production Cumulative } \\
(\mathrm{sm} 3)\end{array}$ & $\begin{array}{l}\text { Gas Production } \\
\text { Cumulative (sm3) }\end{array}$ & $\begin{array}{c}\text { Water cut average } \\
(\%)\end{array}$ & $\begin{array}{l}\text { Peak BHP } \\
\text { (Bar) }\end{array}$ \\
\hline 1 & base Case & $6,476,550$ & $828,900,224$ & 0.954 & 283.896 \\
\hline 2 & Scenario \#1 & $6,493,495$ & $830,278,336$ & 0.949 & 301.997 \\
\hline 3 & Scenario \#2 & $6,510,715$ & $831,706,432$ & 0.947 & 322.526 \\
\hline 4 & Scenario \#3 & $6,542,294$ & $836,500,480$ & 0.943 & 315.692 \\
\hline 5 & Scenario \#4 & $6,588,822$ & $843,135,168$ & 0.939 & 347.729 \\
\hline 6 & Scenario \#5 & $6,570,901$ & $846,228,480$ & 0.940 & 340.375 \\
\hline 7 & Scenario \#6 & $6,587,363$ & $859,280,960$ & 0.939 & 400.018 \\
\hline
\end{tabular}

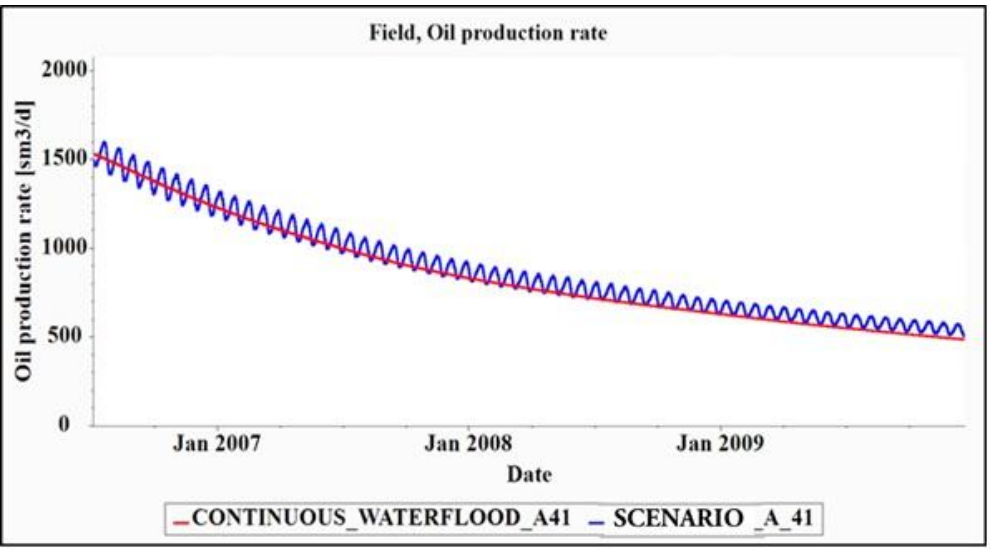

Fig 1511. The oil flow rate in the base case and scenario \#4 


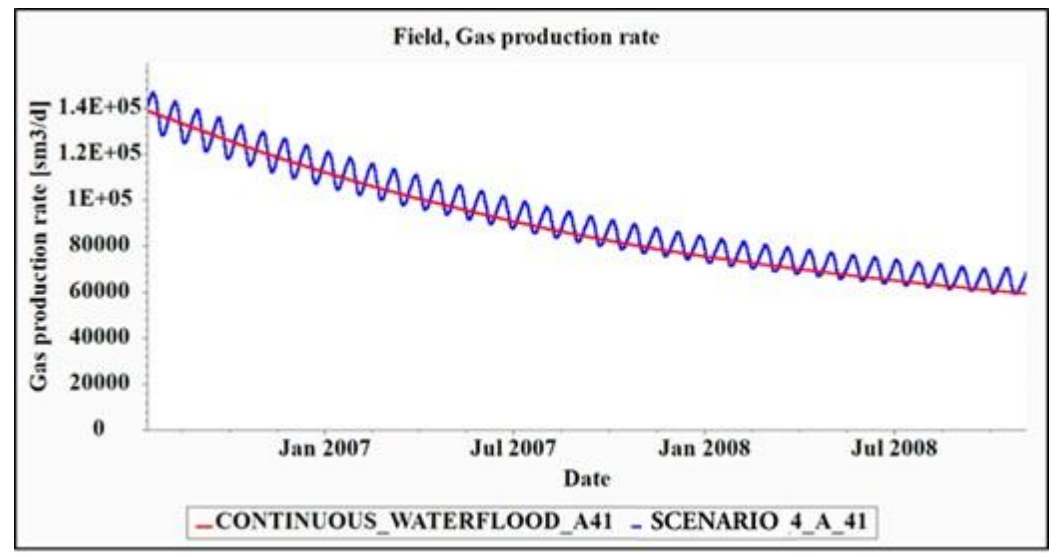

Fig 1612. The gas flow rate of the base case and scenario \#4

b. The influence of cyclic water injection on the reservoir pressure

In addition to the sweeping effect, the cyclic water injection also affects the pressure in the reservoir. The reservoir pressure is dynamically up and down in pressurizing and depressurizing phases alternately.

Fig 17 shows the difference pressure trend between the base cases versus the cyclic water injection scheme. The base case falls steadily, while the pressure cyclic scenario \#4 shows the up and down pressure trend that displays the pressurizing phase with the injection rate is $15.660 \mathrm{sm} 3$ while the depressurizing phase at zero sm3.

Fig 16 exhibits both continuous water injection and cyclic water injection can withstand the reservoir pressure. It means cyclic water injection can maintain reservoir pressure as good as continuous. Another author stated that the injection rate differences, such as cyclic water injection, cause pressure fluctuations reservoir (Shchipanov et al., 2008)

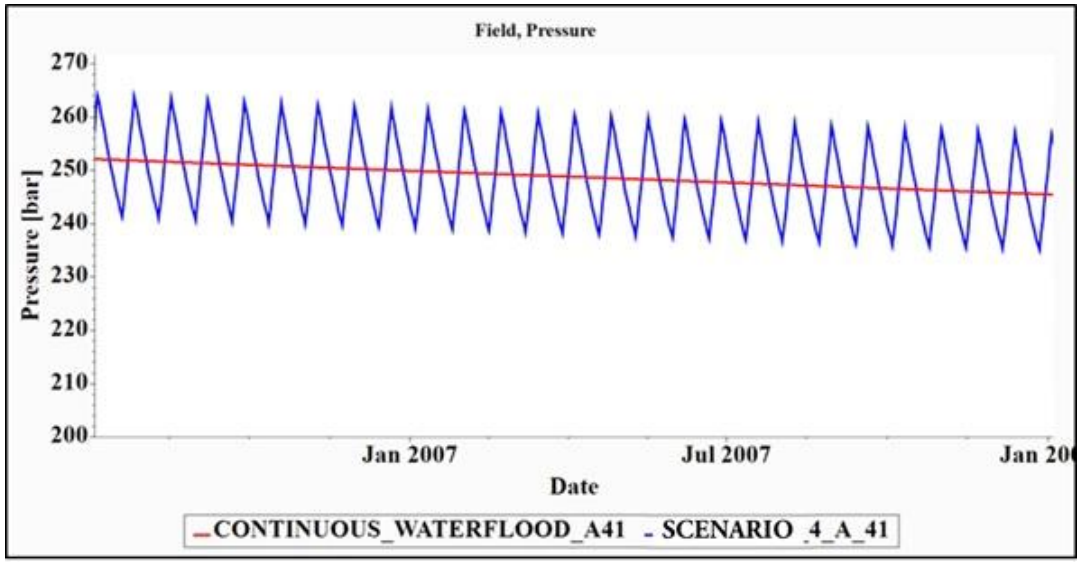

Fig 1713. Pressure reservoir in the base case and scenario \#4

\section{c. The influence of cyclic water injection to oil saturation}

Cyclic water injection affects the sweeping flow path due to pressurizing and depressurizing period. Fig 18 and Fig 19 Fig 15. show significant differences in oil saturation between continuous and cyclic water injection. Some localized parts of the reservoir that are not swept yet by the continuous water injection can be flashed by cyclic water injection. Up to $7.64 \%$ of un-sweep areas can be improved by cyclic water injection. (Stirpe et al., 2004) stated that there are differences in localized effects of cyclic continuous water injection compare to continuous water injection. The difference lies in the zone that has low permeability

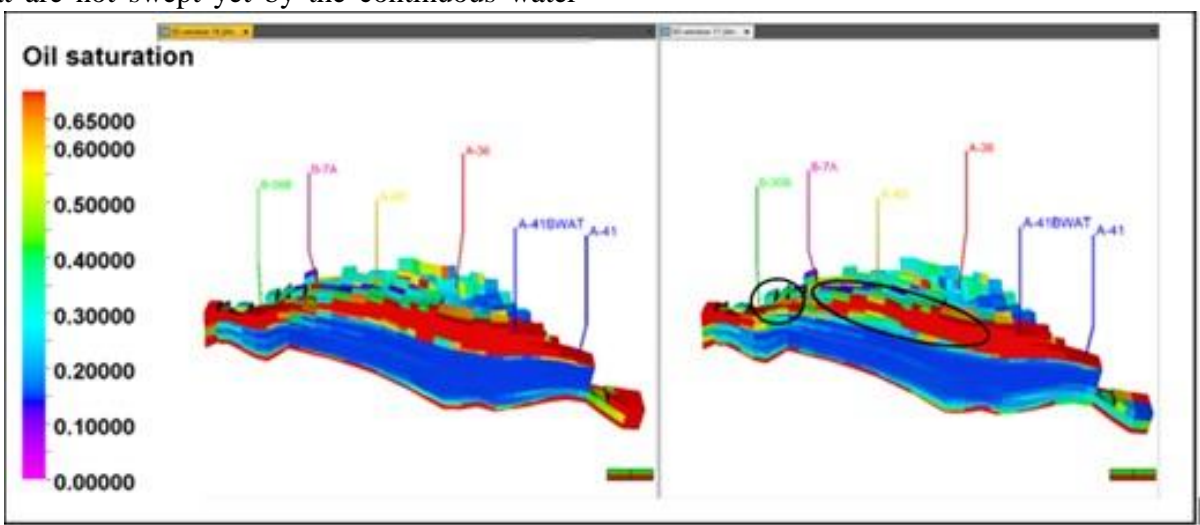

Fig 14. Oil saturation 1 January 2013 (as seen from the west) 


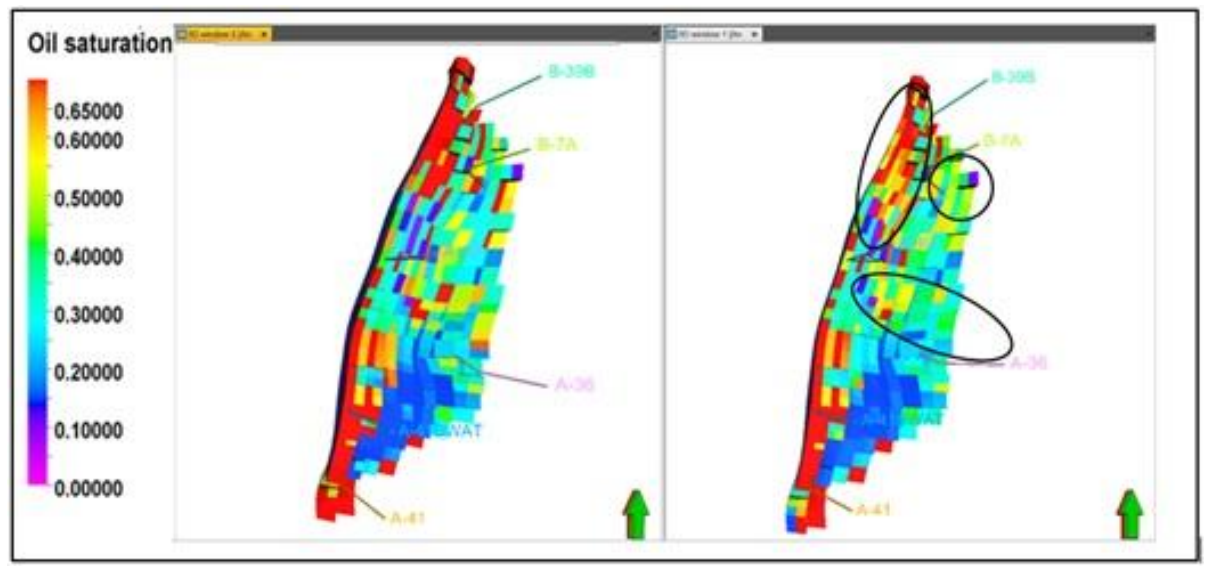

\section{d. Flow-path in scenario \#4}

Fig 20 exhibits the dynamic flow path alteration in cyclic water injection, on July 24, 2006, while the injection is on, the streamline established a flow path through high permeability zone and continuous until the injection closed on July 31, 2006. Once the injection is shut-in, the flow path changed
2013 (seen from above)

dramatically towards the low permeability zone. The streamlined model shows flow path alteration differently until August 13, 2006, that has a different flow path. The water injection penetrates the low permeability zone during the depressurizing phase to sweep the residual oil and gas in that zone.

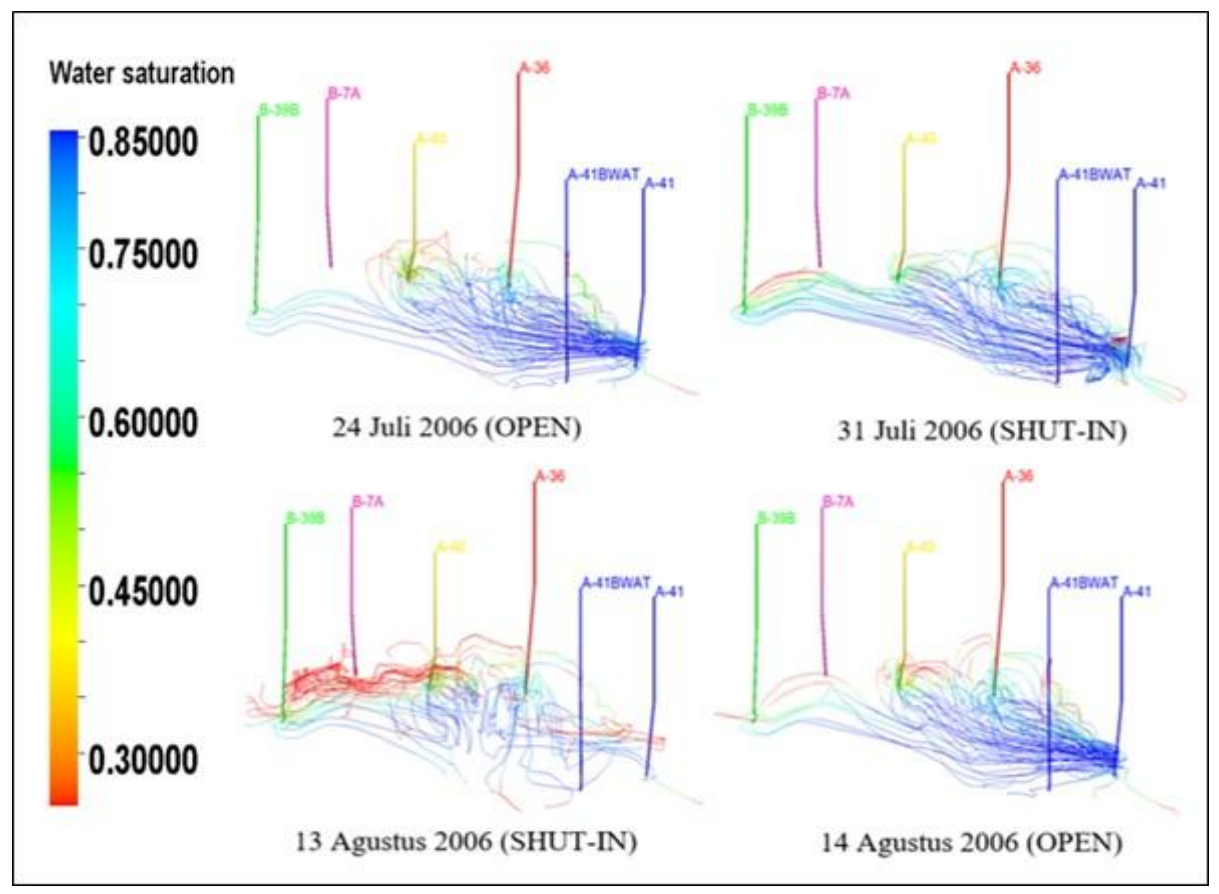

Fig 16. Flow paths in scenario \#4

\section{Conclusion}

Based on the simulation study conducted, the conclusions derived from this study is the connectivity between both A41BWAT and A-41 to the producers is the excellent one. The total tracer reproduced at the production wells reach up to $66.1 \%$ in A-41BWAT and $68.44 \%$ in A-41 that above the $40 \%$ requirement for reliable tracer analysis. Another conclusion is the cyclic water injection increase oil and gas production up to $7.64 \%$ and $10.68 \%$ respectively and decrease water-cut down to $5.45 \%$. And finally, the cyclic water injection can sweep the oil and gas within inaccessible areas of continuous water injection. Approximately up to $7.6 \%$ un-sweep zone can be swept by cyclic water injection

\section{Acknowledgements}

The authors are grateful to the LPPM of the Islamic University of Riau (Kontrak Penelitian No.374/
KONTRAK/LPPM-UIR/4-2018) for the financial support as well as the Petroleum Engineering Department of UIR for their technical support, in this case, it is represented by the Study Centre of Energy, Data Science, and Numerical Simulation.

\section{References}

Al-Najem, A.A., Siddiqui, S., Soliman, M., Yuen, B., 2012. Streamline simulation technology: Evolution and recent trends. Soc. Pet. Eng. - SPE Saudi Arab. Sect. Tech. Symp. $\quad$ Exhib. 2012 696-717. https://doi.org/10.2118/160894-ms

Alhuthali, A.H., Oyerinde, D., Datta-Gupta, A., 2007. Optimal waterflood management using rate control. SPE Reserv. Eval. Eng. 10, 539-551. https://doi.org/10.2118/102478pa

Asadollahi, M., 2012. Waterflooding Optimization for Improved Reservoir Management. Norwegian University of Science and Technology. 
Guan, L., Du, Y., Johnson, S.G., Choudhary, M.K., 2005. Advances of interwell tracer analysis in the petroleum industry. J. Can. Pet. Technol. 44, 12-15. https://doi.org/10.2118/05-05-tn2

Hao, C., Shook, G.M., Taimur, M., Dwarakanath, V., Smith, B.R., Muhammad, S., Masduki, A., Mario, C.C., Putra, K.A.D., 2011. Interwell tracer tests to optimize operating conditions for a surfactant field trial: Design, evaluation and implications. Soc. Pet. Eng. - SPE Enhanc. Oil Recover. Conf. 2011, EORC 2011 2, 1185-1202. https://doi.org/10.2118/144899-ms

Langdalen, H., 2014. Cyclic Water Injection.

Musa, T.A., Ibrahim, A.A., 2012. Modeling of Cyclic Water Injection , East Unity Oil Field - Sudan. J. Sci. Technol. 13.

Perez, D., Salicioni, F., Ucan, S., 2014. Cyclic water injection in San Jorge Gulf Basin, Argentina. SPE Lat. Am. Caribb. Pet. Eng. Conf. Proc. 2, 1556-1575. https://doi.org/10.2118/169403-ms

Putra, D., Umar, M., Futur, L., Rahman, A., 2021. Benefits of the Tracers Test Technique in Improving the Performance of Group Wells. J. Earth Energy Eng. 10, 1-9. https://doi.org/10.25299/jeee.2021.4057

Putra, D.F., 2007. CO2 Injection in an Oil Reservoir with Gas Cap (Compositional Simulation Case at Gullfaks Field Norway). Norwegian University of Science and Technology.

Rublev, A.B., Khuzeev, Y.A., Ishimov, I.A., Fedorov, K.M., 2012. Predictions of cyclic water injection on urnenskoe oil field. Soc. Pet. Eng. - SPE Russ. Oil Gas Explor. Prod. Tech. Conf. Exhib. 2012 3, 1878-1886. https://doi.org/10.2118/162015-ms

Shchipanov, A.A., Surguchev, L.M., Jakobsen, S.R., 2008. Improved oil recovery by cyclic injection and production. Soc. Pet. Eng. - SPE Russ. Oil Gas Tech. Conf. Exhib. 2008 2, 901-911. https://doi.org/10.2118/116873-ms

Stirpe, M.T., Guzman, J., Manrique, E., Alvarado, V., 2004. Cyclic water injection simulations for evaluations of its potential in lagocinco field. Proc. - SPE Symp. Improv. Oil Recover. 2004-April. https://doi.org/10.2523/89378$\mathrm{ms}$

Thrasher, D., Nottingham, D., Stechauner, B., Ohms, D., Stechauner, G., Singh, P.K., Lara Angarita, M., 2016. Waterflood sweep improvement at Prudhoe Bay, Alaska. SPE - DOE Improv. Oil Recover. Symp. Proc. 2016Janua.

Yang, Y., Dai, T., Wang, C., 2006. The reservoir simulation research and extending application about cyclic water injection. Int. Oil Gas Conf. Exhib. China 2006 - Sustain. Growth oil Gas 2, 1119-1128. https://doi.org/10.2118/104440-ms

Zemel, B., 1995. Tracers in the Oil Field.

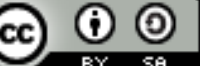

(C) 2021 Journal of Geoscience, Engineering, Environment and Technology. All rights reserved. This is an open access article distributed under the terms of the CC BY-SA License (http://creativecommons.org/licenses/by-sa/4.0/). 